\title{
Internal mixing of the organic aerosol by gas phase diffusion of semivolatile organic compounds
}

\author{
C. Marcolli, B. P. Luo, Th. Peter, and F. G. Wienhold \\ Institute for Atmospheric and Climate Science, ETH Zürich, Zürich, Switzerland \\ Received: 7 September 2004 - Published in Atmos. Chem. Phys. Discuss.: 27 September 2004 \\ Revised: 9 December 2004 - Accepted: 9 December 2004 - Published: 20 December 2004
}

\begin{abstract}
This paper shows that most of the so far identified constituents of the tropospheric organic particulate matter belong to a semivolatile fraction for which gas phase diffusion in the lower troposphere is sufficiently fast to establish thermodynamic equilibrium between aerosol particles. For the first time analytical expressions for this process are derived. Inspection of vapor pressure data of a series of organic substances allows a rough estimate for which substances this mixing process must be considered. As general benchmarks we conclude that for typical aerosol radii between 0.1 and $1 \mu \mathrm{m}$ this mixing process is efficient at $25^{\circ} \mathrm{C}$ for polar species with molecular weights up to 200 and for non-polar species up to 320 . At $-10^{\circ} \mathrm{C}$, these values are shifted to 150 for polar and to 270 for non-polar substances. The extent of mixing of this semivolatile fraction is governed by equilibrium thermodynamics, leading to a selectively, though not completely, internally mixed aerosol. The internal mixing leads to a systematic depression of melting and deliquescence points of organic and mixed organic/inorganic aerosols, thus leading to an aerosol population in the lower troposphere which is predominantly liquid.
\end{abstract}

\section{Introduction}

The tropospheric aerosol is a complex mixture of inorganic and organic components. Depending on location, organic species typically represent $20-50 \%$ of the aerosol mass (Dick et al., 2000; Zappoli et al., 1999; Kriváscy et al., 2001). They constitute a very complex mixture covering a wide range of polarity and molecular weights (Rogge et al., 1993). Up to

Correspondence to: C. Marcolli

(claudia.marcolli@env.ethz.ch) now, the mixing and the physical state of the organic species in the tropospheric aerosol are unclear. Experimental and theoretical thermodynamic considerations indicate that the organic particulate matter remains liquid down to very low relative humidity, if it consists of a high enough number of miscible components. It therefore absorbs/desorbs molecules from/to the gas phase (Marcolli et al., 2004). This assumption is in accordance with smog chamber measurements, which are best described by a gas/particle absorptive partitioning model (Odum et al., 1996; Liang et al., 1997). Considering the composition of the so far isolated organic matter (Rogge et al., 1993), which comprises long chain alkanes as well as short chain dicarboxylic acids, at least two liquid phases are expected: a water-soluble and a water-insoluble one. Depending on relative humidity, the water-soluble one will also contain water and inorganic ions.

If a completely internally mixed aerosol is assumed, the partitioning between the gas and the condensed phases can be calculated for a given aerosol composition assuming equilibrium thermodynamics. Such an approach has been described by Pankow (2003). Whether indeed an internal mixture prevails, depends on the efficiency of the mixing processes in the atmosphere. In this work, we estimate the efficiency of mixing by gas phase diffusion for the organic aerosol fraction.

Different processes promote the mixing of the organic aerosol. Sources of primary organic carbon usually emit a multitude of different substances (Seinfeld and Pandis, 1998) with compounds originating from the same source at least partly internally mixed, and coagulation downstream of the source further enhancing internal mixing. Depending on the volatility of the organic compounds, an additional mixing process is gas phase diffusion. This process may establish

(C) 2004 Author(s). This work is licensed under a Creative Commons License. 
thermodynamic equilibrium between particles, provided the motion of an air parcel gives the diffusion process enough time.

So far, theoretical studies of transfer processes of volatile species to and from aerosol particles have focused on the equilibration with the gas phase (Wexler and Seinfeld, 1990; Meng and Seinfeld, 1996) without explicitly addressing the coupling between the condensed phases by transport through the gas phase. In this study, particle/particle equilibration is explicitly treated leading to an analytical expression for the time constant of this process. This expression is applied to a broad spectrum of organic aerosol constituents for an estimate of its significance.

\section{Analytical solution of internal mixing via the gas phase}

As an approximation for the equilibration process of complex aerosol mixtures we consider two monodisperse liquid particle distributions of identical chemical composition except for one species, which is present in different amounts. Gas phase diffusion leads to molecule fluxes between the gas and the liquid phases and between the two particle distributions. In our analysis, the particle distributions and the gas phase form a closed system, which is more general than treating gas/particle phase exchange for each distribution separately. We restrict the analytical solution of the differential equations given below to the case of particle distributions with equal radii. This avoids the algebraic complexity of the unrestricted case, yet provides important insight into the equilibration process. Further, we assess the applicability of this restricted case by comparison with the general case of nonequal radii analyzed by Wienhold et al. (2005) ${ }^{1}$.

The molecule number densities of the organic species in the liquid phase, $n_{1,2}^{\ell}$ (taken per unit volume of air), change in time as

$\frac{d n_{1,2}^{\ell}}{d t}=4 \pi r_{1,2} N_{1,2} D\left(1+\beta_{1,2}\right)^{-1}\left[n^{g}-\frac{n_{1,2}^{\ell}}{h_{1,2}}\right]$,

where the indices 1 and 2 refer to particle distributions 1 and 2 , respectively, $r_{1,2}$ are the particle radii, $N_{1,2}$ are the particle number densities, $n^{g}$ is the organic molecule number density in the gas phase, $\beta_{1,2}=4 D / \alpha r_{1,2} v$, with $\alpha$ being the accommodation coefficient, $v$ the mean molecular speed, and $D$ the molecular diffusivity in the gas phase. With the dimensionless Henry's law constant of the corresponding species $H$, defined as the ratio between the liquid phase and the gas phase number density under thermodynamic equilibrium conditions, $h_{1,2}$ read

$h_{1,2}=(4 \pi / 3) r_{1,2}^{3} N_{1,2} H$.

\footnotetext{
${ }^{1}$ Wienhold, F. G., Marcolli, C., Luo, B. P., and Peter, Th.: Equilibration of volatile species in atmospheric aerosol: Analytical treatment, Atmos. Environ., to be submitted, 2005.
}

Mass conservation requires

$n^{\text {tot }}=n_{1}^{\ell}+n_{2}^{\ell}+n^{g}$

to be constant and couples the differential equations for the liquid phase number densities:

$$
\begin{aligned}
\frac{d n_{1,2}^{\ell}}{d t}= & 4 \pi r_{1,2} N_{1,2} D\left(1+\beta_{1,2}\right)^{-1} \\
& \times\left[n^{\text {tot }}-n_{2,1}^{\ell}-\left(1+\frac{1}{h_{1,2}}\right) n_{1,2}^{\ell}\right] .
\end{aligned}
$$

Assuming now the radii to be equal, $r=r_{1}=r_{2}$,

$$
\begin{aligned}
n_{1,2}^{\ell}(t) & =n_{1,2}^{\ell, \infty} \\
+ & \frac{h_{1,2}\left[\left(n_{1}^{\ell, 0}-n_{1}^{\ell, \infty}\right)+\left(n_{2}^{\ell, 0}-n_{2}^{\ell, \infty}\right)\right]}{h_{1}+h_{2}} e^{-t / \tau^{g}} \\
\quad \pm & \frac{h_{2}\left(n_{1}^{\ell, 0}-n_{1}^{\ell, \infty}\right)-h_{1}\left(n_{2}^{\ell, 0}-n_{2}^{\ell, \infty}\right)}{h_{1}+h_{2}} e^{-t / \tau^{\ell}}
\end{aligned}
$$

solve Eq. (4) for the initial $(t=0)$ number densities $n_{1,2}^{\ell, 0}$ with the equilibrium number densities given by $n_{1,2}^{\ell, \infty}=h_{1,2} n^{\text {tot }} /\left(1+h_{1}+h_{2}\right)$. The time evolution of both liquid phases is governed by two distinct time exponentials, while Eqs. (3) and (5) lead to the gas phase solution for the initial number density $n^{g, 0}$ :

$n^{g}(t)=n^{g, \infty}+\left[n^{g, 0}-n^{g, \infty}\right] e^{-t / \tau^{g}}$.

Here, $n^{g, \infty}=n^{\text {tot }} /\left(1+h_{1}+h_{2}\right)$ denotes the equilibrium gas phase number density. The time constant

$\tau^{\ell}=\frac{H r^{2}}{3 D}(1+\beta)$

describes the equilibration among the liquid particles by diffusion through the gas phase, while the time constant for the equilibration between the gas and the liquid phases is given by

$\tau^{g}=\frac{\tau^{\ell}}{1+(4 \pi / 3) H r^{3}\left(N_{1}+N_{2}\right)}$.

Interestingly, expression (7) is identical to the time constant for the equilibration between a single droplet and the gas phase in an "open" system, i.e. with the partial pressure held constant. Conversely, the interaction between particles via the gas phase in a "closed" system has not been treated analytically before. The exact shape of Eq. (6) can be traced back to the condition $r_{1}=r_{2}$, resulting in a buffering of the amounts of trace gas shifted between the distributions after the gas phase has come to equilibrium. For $r_{1} \neq r_{2}$, Wienhold et al. (2005) $)^{1}$ provide a full analytical solution and derive approximations for the limits of (a) non-equal radii with preferred partitioning into the gas phase and (b) near-equal radii or preferred partitioning into the liquid phase without 
restricting the radii. While (a) reflects the situation of decoupled liquid reservoirs, in (b) the liquid phases are coupled and the time constant for the flux between liquid reservoirs can be approximated by

$\tau^{\ell} \cong \frac{H}{3 D} \frac{r_{1}^{3} N_{1} r_{2}^{3} N_{2}}{r_{1}^{3} N_{1}+r_{2}^{3} N_{2}}\left(\frac{1+\beta_{1}}{r_{1} N_{1}}+\frac{1+\beta_{2}}{r_{2} N_{2}}\right)$.

The relative error of Eq. (9) with respect to the exact analytical solution rises to $\sim 10 \%$ for equal partitioning of the species in the gas and liquid phases. Also, $\tau^{\ell}$ from Eq. (9) is always smaller than or equal to $\tau^{\ell}$ from Eq. (7) when evaluated at $r=\max \left(r_{1}, r_{2}\right)$, which makes Eq. (7) a widely applicable formula.

Figure 1 shows examples of the equilibration process starting from the following non-equilibrium situations: the organic species under consideration constitutes $20 \mathrm{wt} \%$ of the particles in distribution 1 and $0 \mathrm{wt} \%$ in distribution 2, and the gas phase contains half as much of the organic species as distribution 1 in the first case (Figs. 1a and b) and nothing in the second case (Figs. 1c and d). In the third case (Figs. 1e and f) the gas phase contains $90 \%$ of the organic species under consideration, distribution $110 \%$ corresponding to $2 \mathrm{wt} \%$ of this distribution and distribution 2 nothing. This case is expected for semivolatile organic compounds that are chemically formed in the gas phase and subsequently condense on aerosol particles.

The particle number densities of the distributions are $N_{1}=400 \mathrm{~cm}^{-3}$ and $N_{2}=200 \mathrm{~cm}^{-3}$. A molecular weight of 300 is assumed for the organic species. The calculations have been performed for an ambient temperature of $293 \mathrm{~K}$ and a dimensionless Henry's law constant of $3 \times 10^{14}$, corresponding to a vapor pressure of $\sim 2 \times 10^{-10} \mathrm{mmHg}$ for the pure substance. The analytical and numerical solutions have been calculated for monodisperse size distributions with particle radii of $0.1 \mu \mathrm{m}$. The numerical solution allows in addition for polydisperse (e.g. initially lognormal) distributions to test the sensitivity on finite size distribution widths, as well as for changes of size due to evaporation/condensation effects. Figure 1 shows that all three solutions yield very similar results: the gas phase rapidly reaches equilibrium with a time constant $\tau^{g}=7 \mathrm{~min}$. However, the mass transport between the particle distributions is slow: $\tau^{\ell} \approx 100 \mathrm{~h}$. The very good agreement between the numerical solutions for the monodisperse and polydisperse distributions enables us to apply Eqs. (5) and (6) to particle size distributions under real atmospheric conditions with a high degree of accuracy. The non-monotonous time evolution of the liquid phase as displayed in Fig. 1 results from superposition of exponential relaxations with different time constants as seen in Eqs. (5). Such a time evolution cannot be expressed by simpler analytical treatments given in the literature (e.g. Meng and Seinfeld, 1996) which neglect the liquid phase coupling and thereby describe the equilibration of each liquid phase by a single monotonous time exponential.
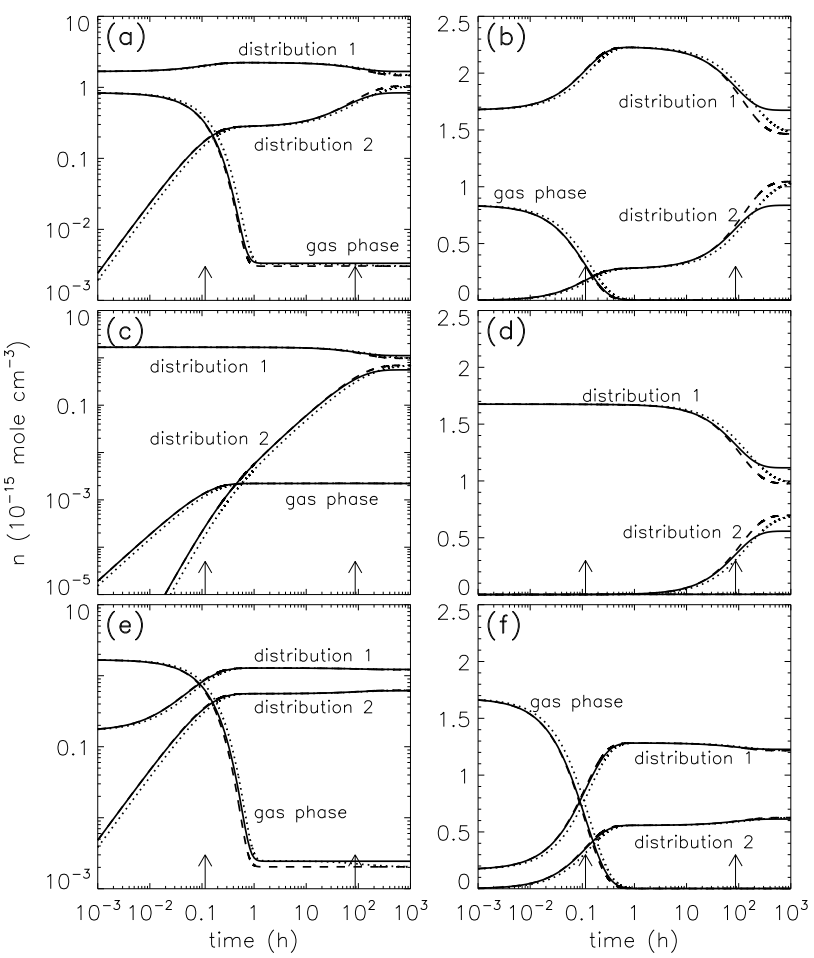

Fig. 1. Time evolution of equilibration of an organic species between two particle distributions and the gas phase. Initial conditions: (a) and (b) distribution 1 contains $2 / 3$ of the organic species of interest (corresponding to $20 \mathrm{wt} \%$ ), the gas phase the remaining $1 / 3$, distribution 2 is empty; (c) and (d) the organic species is present only in distribution 1 (again $20 \mathrm{wt} \%$ ); (e) and (f) $90 \%$ of the organic species is in the gas phase and $10 \%$ in distribution 1 (corresponding to $2 \mathrm{wt} \%$ of distribution 1), distribution 2 is empty. (a), (c), and (e) show the evolution of the number concentration $n$ in logarithmic, (b), (d), and (f) in linear scales. Solid lines: analytical solutions Eqs. (5-6) neglecting size changes. Dashed lines: numerical simulation for a monodisperse particle size distribution including size changes due to evaporation and condensation of the organic component. Dotted lines: numerical simulation for initially lognormally (mode radius $=0.0718 \mu \mathrm{m}$, value chosen to match the volume of the monodisperse case; width $\sigma=1.6$ ) distributed particle ensembles. Arrows: particle/particle and gas/particle equilibrium time constants, Eqs. (7-8), respectively, which are independent of the initial conditions.

\section{Atmospheric implications}

The time constant for the internal mixing of semivolatile components $\tau^{\ell}$ is proportional to the dimensionless Henry's law constant $\mathrm{H}$. The assessment of $\tau^{\ell}$ for actual tropospheric conditions requires Henry's law constants of typical organic tropospheric aerosol constituents.

\subsection{Ideal solutions}

The Henry's law constant of a substance depends on both, the volatility of the pure substance and the solubility of a 


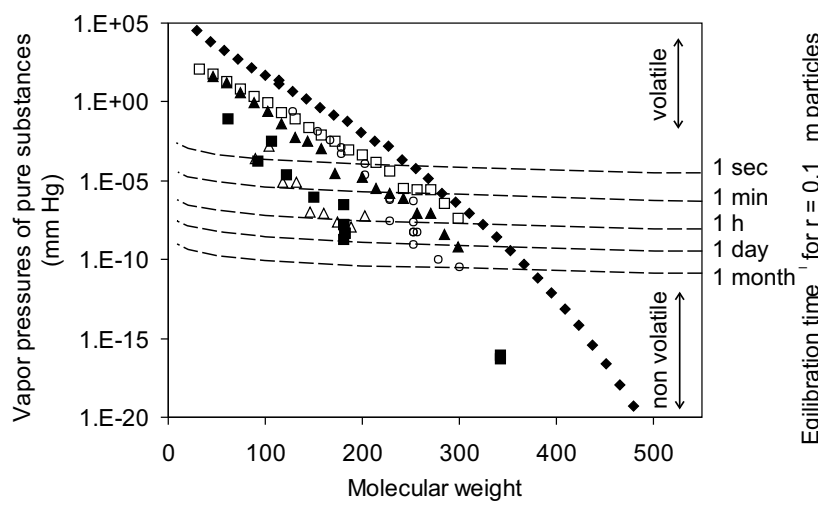

Fig. 2. Vapor pressures of pure substances of atmospheric importance at $25^{\circ} \mathrm{C}$ sorted by molecular weight: alkanes (black $\diamond$ ), alkanols $(\square)$, alkanoic acids $(\boldsymbol{\Delta})$, dicarboxylic acids $(\triangle)$, polyols $(\boldsymbol{\square})$, $\mathrm{PAH}(\bigcirc)$. The right hand axis indicates time constants for equilibration between particles $\tau^{\ell}$ according to Eqs. (7) and (10) for typical atmospheric conditions $\left(r=0.1 \mu \mathrm{m}, D=0.1 \mathrm{~cm}^{2} / \mathrm{s}, \rho=1.0 \mathrm{~g} / \mathrm{cm}^{3}\right.$, $v=200 \mathrm{~m} / \mathrm{s}, \alpha=1$ ).

substance in the respective solvent. Mostly, water is used as a reference solvent for compilations of Henry's law constants. However, for moderate relative humidities, the water-soluble organic fraction forms a concentrated solution that is not well represented by Henry's law constants for infinitely dilute systems. Moreover, hydrophobic substances such as alkanes do not partition readily into the aqueous phase. Rather, they will partition into the water-insoluble organic fraction consisting of a wide range of hydrophobic substances. Thus, for a representative estimate of the time constants for an organic species dissolving into a predominantly organic solvent, dissolution into an ideal solvent was assumed (Raoult's law). In this case, the Henry's law constants can be estimated based on the vapor pressures of the pure substances, $p^{0}$, as

$H \approx \frac{\rho R T}{M p^{0}}$,

where $R$ is the universal gas constant, $T$ the absolute temperature, $\rho$ the mass density and $M$ the molar mass of the investigated organic compound. With this approximation, the time constant for equilibration by gas phase diffusion can be expressed as a function of the vapor pressures of the pure substances.

Figure 2 shows vapor pressures of different substance classes at $25^{\circ} \mathrm{C}$ as a function of molecular weight. For the alkanes (Wilhoit and Zwolinski, 1971), the alkanols (Howard and Meylan, 1997), the alkanoic acids up to ten carbon atoms, small polyols such as glycerol (Howard and Meylan, 1997) and the polycyclic aromatic hydrocarbons (PAH) (Howard and Meylan, 1997; Yaws, 1994), measured values of the liquids and extrapolated values for the supercooled liquids are presented. For the long chain alkanoic acids (Tao and McMurry, 1989), the dicarboxylic acids (Howard and
Meylan, 1997; Tao and McMurry, 1989; Chattopadhyay et al., 2001), and the larger polyols such as mannitol, glucose or raffinose (Howard and Meylan, 1997) either estimated or measured values of the solids are given. Figure 2 shows that the vapor pressure is a function of both the molecular weight and the polarity of the substances.

On the right axis in Fig. 2, equilibration time constants are indicated as a function of the vapor pressures of the pure substances for the case of $r=0.1 \mu \mathrm{m}$ particles, a diffusion coefficient $D=0.1 \mathrm{~cm}^{2} / \mathrm{s}$, a mean molecular speed $v=200 \mathrm{~m} / \mathrm{s}$, and an accommodation coefficient $\alpha=1$. The dimensionless Henry's law constant is calculated as a function of vapor pressures and molecular weights with densities of $\rho=1.0 \mathrm{~g} / \mathrm{cm}^{3}$. With mixing times longer than 1 week, equilibration by gas phase diffusion for substances with vapor pressures lower than $10^{-10} \mathrm{mmHg}$ becomes ineffective. These substances can therefore be considered as non-volatile. Conversely, as a criterion from Eq. (2),

$(4 \pi / 3) H r^{3}\left(N_{1}+N_{2}\right)=1$

must be satisfied for species to partition equally between the condensed and the gas phase. This criterion is approximately fulfilled for the 1 min line in Fig. 2. Saxena and Hildemann (1996) identified specific organic compounds that are likely to contribute to the water-soluble organic fraction of the aerosol based on the vapor pressure and aqueous solubility of the pure substances. Based on this study, substances with vapor pressures above $\sim 1 \mathrm{mmHg}$ can be assumed to be too volatile to partition effectively into the liquid phase. Thus, substances with vapor pressures in between these two limits, $10^{0}-10^{-10} \mathrm{mmHg}$, are sufficiently non-volatile to be present in the liquid phase and exhibit simultaneously a sufficiently high vapor pressure to establish thermodynamic equilibrium between the aerosol particles on atmospheric timescales ( $<1$ week). Thus, they can be considered as semivolatile. At $25^{\circ} \mathrm{C}$, this semivolatile fraction has molecular weights up to 200 for polar, hydrophilic substances and up to 320 for non-polar, hydrophobic substances.

The estimate of the equilibration time constants shown in Fig. 2 depends on several factors, the most important ones being particle size and temperature. Compared to particles with $r=0.1 \mu \mathrm{m}$ used to calculate the equilibration time constants, particles with $r=1 \mu \mathrm{m}$ equilibrate more slowly by a factor of $\approx 40$. Considering that the relevant range in vapor pressure covers about ten orders of magnitude, particle size effects are by far dominated by variations in the Henry's law constants, which depend on temperature and deviations from ideality. Based on either measured or extrapolated values from a compilation by Yaws (1994), it can be concluded that a temperature reduction from $25^{\circ} \mathrm{C}$ to $-10^{\circ} \mathrm{C}$, leads to a decrease in vapor pressure by one to three orders of magnitude depending on the specific substance. Thus, at $-10^{\circ} \mathrm{C}$ equilibration starts to become ineffective for polar substances with molecular weights larger than 150 and for non-polar substances with molecular weights larger than 270 . 
For high particle number concentrations coagulation becomes an important mixing process that will most strongly affect ultrafine particle number densities. An overview of the timescales of mixing by coagulation is given by Kanakidou et al. (2004). The states of mixing resulting from coagulation and equilibration by gas phase diffusion are not equal: a hydrophobic substance will not partition into a hydrophilic particle because of its high activity in such a medium. Coagulation, however, can lead to internal mixtures of species that are not miscible with each other: if a hydrophobic particle coagulates with a hydrophilic one, substances such as alkanes and polyols will be present in the same particle but in separate phases.

\subsection{Non-ideal solutions}

For internally mixed liquid aerosol particles, the partial pressure of each individual substance depends on the vapor pressure of the pure substance and its activity in the solution. The time constants for equilibration have been calculated based on the assumption that the substances dissolve into an ideal solvent. In the atmosphere, deviations from ideality may considerably alter the solubility, thus leading to increased or reduced vapor pressures compared with the ideal case. Model calculations of activity coefficients are needed for typical tropospheric aerosol compositions to treat this effect. Moreover, chemical reactions are not taken into account for the calculation of equilibration times. For example, neutralization reactions by ammonia can reduce the effective Henry's law constants for organic acids and prolong the mixing time of species such as oxalic acid. Also, polymerization reactions may lower the vapor pressure and increase the amount of non-volatile organic matter. However, non-ideality will not affect the principal relevance of internal mixing by gas phase diffusion since there is always a range of semivolatile species (hence of $H$ and $M$ ), for which it will be effective.

\subsection{Observations}

Most of the so far identified constituents of the particulate matter belong to the semivolatile fraction (Rogge et al., 1993). The products from monoterpene oxidation with molecular weights between 130 and 200 have indeed been observed in the gas and in the aerosol phase (Yu et al., 1999). The same is true for PAH and dicarboxylic acids with up to 10 carbon atoms (Fernández et al., 2002; Limbeck et al., 2001; Kavouras and Stephanou, 2002).

For urban samples, Allen et al. (1996) have observed that PAH with molecular weights between 178 and 202 were approximately evenly distributed between the fine and coarse particles. PAH with molecular weights greater than 228 were associated primarily with the fine particle fraction. They assumed that PAH are emitted in the gas phase or associated with fine particles and proposed slow mass transfer by vapor-

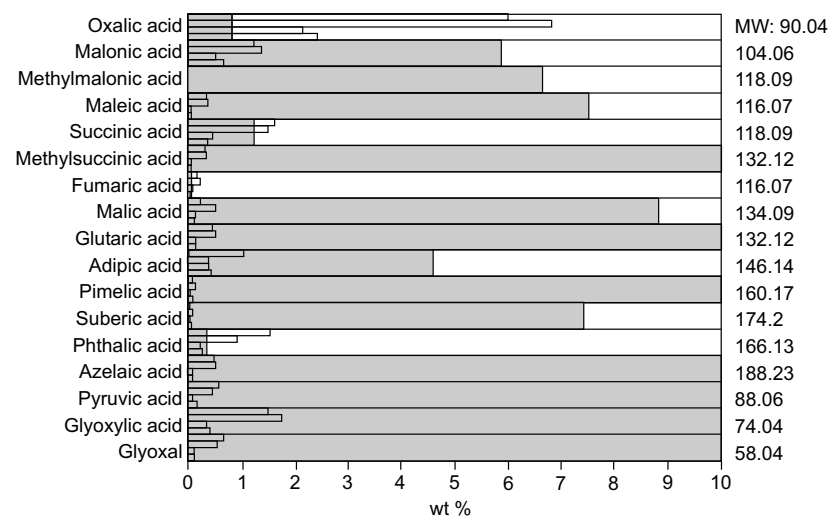

Fig. 3. Abundance of organic compounds in the water-soluble organic fraction of four samples from Tokyo, 1992, (transparent bars, four for each compound) (Sempéré and Kawamura, 1994) compared with their solubility in an ideal solvent (grey bars).

ization and condensation to explain the observed PAH partitioning among particle size fractions whereby higher molecular weight $\mathrm{PAH}$ do not attain an equilibrium distribution among urban aerosols. This hypothesis is confirmed by our estimates, which predict equilibration times of seconds for PAH with molecular weights below 200 and hours for the ones with molecular weights above 250. Likewise, Falkovich et al. (2004) describe the redistribution of low-molecularweight $\mathrm{PAH}$ and pesticides from small particle to larger particle sizes during dust events. High-molecular weight $\mathrm{PAH}$ as well as levoglucosan always remained in the submicron particle size bins, in which they were originally emitted to the atmosphere.

The high degree of internal mixing of the organic aerosol particle fraction has been shown by single particle measurements using on-line mass spectrometry. Based on these measurements, it was concluded that the internal mixture of organic components and sulfate can be regarded as a general characteristic of tropospheric aerosols in the continental region (Lee et al., 2002). Selective mixing is confirmed by the observation that hydrocarbons are rather associated with soot, whereas oxidized organics with sulfate particles (Lee et al., 2003).

Mochida et al. (2003) have studied the size distributions of $\mathrm{C}_{2}-\mathrm{C}_{4}$ dicarboxylic acids in aerosols in the marine boundary layer. They found that over the remote ocean these substances were relatively abundant in the supermicron particles whereas over the coastal ocean they were mostly present in submicron particles. Backward trajectory analysis showed that air masses were mostly of continental origin from East Asia, suggesting a shift of the diacids' size distributions from small to larger particles during transport. The $\mathrm{C}_{2}-\mathrm{C}_{4}$ dicarboxylic acids exhibit molar Henry's law constants in water in the range from $10^{6}-10^{8} \mathrm{M} / \mathrm{atm}$ and vapor pressures from $10^{-3}-10^{-7} \mathrm{mmHg}$ (Saxena and Hildemann, 1996; Howard and Meylan, 1997). Based on both, Henry's law constants 
and vapor pressures, thermodynamic equilibrium between particles should be established within minutes. Given the decreasing concentration of non-sea-salt sulfate aerosol and assuming a constant level of sea-salt particles, the measurements are indeed in agreement with instantaneous repartitioning of the $\mathrm{C}_{2}-\mathrm{C}_{4}$ diacids between the developing inorganic aerosol populations.

\subsection{Aerosol phase}

The internal mixing of the organic aerosol constituents leads to a systematic depression of melting and deliquescence points of organic and mixed organic/inorganic aerosols (Marcolli et al., 2004). Figure 3 shows the abundance of organic substances in the water-soluble organic fraction of samples from Tokyo, 1992, in terms of weight percent (Sempéré and Kawamura, 1994). The grey bars give the calculated solubilities assuming ideal behavior (Marcolli et al., 2004). The listed substances will be internally mixed within a second (e.g. pyruvic acid) to an hour (azelaic acid) due to equilibration by gas phase diffusion. The comparison shows that the saturation solubility exceeds the abundance of most substances in the water-soluble organic fraction, thus leading to an aerosol population in the lower troposphere which is predominantly liquid irrespective of the relative humidity conditions.

\section{Conclusions}

The time constants for equilibration between aerosol particles by gas phase diffusion have been calculated analytically under the assumption of monodisperse particle size distributions, and the dependence on this assumption has been demonstrated to be weak. This process contributes considerably to the internal mixing of the organic aerosol particle fraction in the lower troposphere with typical radii between 0.1 and $1 \mu \mathrm{m}$. Inspection of vapor pressure data for a series of organic substances allows a rough estimate for which substances this mixing process must be considered. As general benchmarks we conclude that this mixing process is efficient for polar species with molecular weights up to 200 and for non-polar species up to 320 at $25^{\circ} \mathrm{C}$, shifting to 150 and 270 at $-10^{\circ} \mathrm{C}$, respectively. Most of the so far identified constituents of the particulate matter exhibit molecular weights in this range. In order to estimate the overall significance of this mixing process, the whole organic particulate matter has to be characterized better with respect to vapor pressures, or molecular weights and polarities as surrogate properties.

Equilibration by gas phase diffusion leads to a selective albeit not complete - internal mixture of the organic aerosol, whereby the degree of mixing is given by the activity of the semivolatile species in the aerosol particles. A high degree of internal mixing of the organic fraction with inorganic constituents is experimentally confirmed by an increasing num- ber of single-particle measurements (Murphy and Thomson, 1997; Lee et al., 2002, 2003). Moreover, the internal mixing leads to a systematic depression of melting and deliquescence points of organic and mixed organic/inorganic aerosols, thus leading to an aerosol population in the lower troposphere which is predominantly liquid (Marcolli et al., 2004).

Acknowledgements. This work was supported by the Swiss National Foundation under contract No. 21-63328.00.

Edited by: U. Lohmann

\section{References}

Allen, J. O., Dookeran, N. M., Smith, K. A., Sarofim, A. F., Taghizadeh, K., and Lafleur, A. L.: Measurement of polycyclic aromatic hydrocarbons associated with size-segregated atmospheric aerosols in Massachusetts, Environ. Sci. Technol., 30, 1023-1031, 1996.

Chattopadhyay, S., Tobias, H. J., and Ziemann, P. J.: A method for measuring vapor pressures of low-volatility organic aerosol compounds using a thermal desorption particle beam mass spectrometer, Anal. Chem. 73, 3797-3803, 2001.

Dick, W. D., Saxena, P., and McMurry, P. H.: Estimation of water uptake by organic compounds in submicron aerosols measured during the Southeastern Aerosol and Visibility Study, J. Geophys. Res., 105(D1), 1471-1479, 2000.

Falkovich, A. H., Schkolnik G., Ganor. E., and Rudich, Y.: Adsorption of organic compounds pertinent to urban environments onto mineral dust particles, J. Geophys. Res., 109, D02208, doi:10.1029/2003JD003919, 2004.

Fernández, P., Grimalt, J. O., and Vilanova, R. M.: Atmospheric gas-particle partitioning of polycyclic aromatic hydrocarbons in high mountain regions of Europe, Environ. Sci. Technol., 36, 1162-1168, 2002.

Howard, Ph. H. and Meylan, W. M.: Handbook of Physical Properties of Organic Chemicals, Lewis Publishers, 1997.

Kanakidou, M., Seinfeld, J. H., Pandis, S. N., Barnes, I., Dentener, F. J., Facchini, M. C., van Dingenen, R, Ervens, B., Nenes, A., Nielsen, C. J., Swietlicki, E., Putaud, J. P., Balkanski, Y., Fuzzi, S., Horth, J., Moortgat, G. K., Winterhalter, R., Myhre, C. E. L., Tsigaridis, K., Vignati, E., Stephanou, E. G., and Wilson, J.: Organic aerosol and global climate modelling: a review, Atmos. Chem. Phys. Discuss., 4, 5855-6024, 2004,

SRef-ID: 1680-7375/acpd/2004-4-5855.

Kavouras, I. G. and Stephanou, E. G.: Gas/particle partitioning and size distribution of primary and secondary carbonaceous aerosols in public buildings, Indoor Air, 12, 17-32, 2002.

Krivácsy, Z., Gelencsér, A., Kiss, G., Mészáros, E., Molnár, Á., Hoffer, A., Mészáros, T., Sárvári, Z., Temesi, D., Varga, B., Baltenperger, U., Nyeki, S., and Weingartner, E.: Study on the chemical character of water soluble organic compounds in fine atmospheric aerosol at the Jungfraujoch, J. Atmos. Chem., 39, 235-259, 2001.

Lee, S.-H., Murphy, D. M., Thomson, D. S., and Middlebrook, A. M.: Chemical components of single particles measured with Particle Analysis by Laser Mass Spectrometry (PALMS) during the Atlanta SuperSite Project: Focus on organic/sulfate, 
lead, soot and mineral particles, J. Geophys. Res., 107(D1), doi:10.1029/2000JD000011, 2002.

Lee, S.-H., Murphy, D. M., Thomson, D. S., and Middlebrook, A. M.: Nitrate and oxidized organic ions in single particle mass spectra during the 1999 Atlanta Supersite Project, J. Geophys. Res., 108(D7), 8417, doi:10.1029/2001JD001455, 2003.

Liang, C., Pankow, J. F., Odum, J. R., and Seinfeld, J. H.: Gas/particle partitioning of semivolatile organic compounds to model inorganic, organic, and ambient smog aerosols, Environ. Sci. Technol. 31, 3086-3092, 1997.

Limbeck, A., Puxbaum, H., Otter, L., and Scholes M. C.: Semivolatile behavior of dicarboxylic acids and other polar organic species at a rural background site (Nylsvley, RSA), Atmos. Environ., 35, 1853-1862, 2001.

Marcolli, C., Luo, B. P., and Peter, Th.: Mixing of the organic aerosol fractions: liquids as the thermodynamically stable phases, J. Phys. Chem. A, 108, 2216-2224, 2004.

Meng, Z. and Seinfeld, J. H.: Time scales to achieve atmospheric gas-aerosol equilibrium for volatile species, Atmos. Environ., 30, 2889-2900, 1996.

Mochida, M., Umemoto, N., Kawamura, K., and Uematsu, M.: Bimodal size distribution of $\mathrm{C}_{2}-\mathrm{C}_{4}$ dicarboxylic acids in the marine aerosols, Geophys. Res. Lett., 30(13), 1672, doi:10.1029/2003GL017451, 2003.

Murphy, D. M., and Thomson, D. S.: Chemical composition of single aerosol particles at Idaho Hill: Negative ion measurements, J. Geophys. Res., 102(D5), 6353-6368, 1997.

Odum, J. R., Hoffmann, Th., Bowman, F., Collins, D., Flagan, R. C., and Seinfeld, J. H.: Gas/particle partitioning and secondary organic aerosol yields, Environ. Sci. Technol., 30, 2580-2585, 1996.

Pankow, J. F.: Gas/particle partitioning of neutral and ionizing compounds to single and multi-phase aerosol particles. 1. Unified modeling framework, Atmos. Environ., 37, 3323-3333, 2003.
Rogge, W. F., Mazurek, M. A., Hildemann, L. M., Cass, G. R., and Simoneit, B. R. T.: Quantification of urban organic aerosols at a molecular level: Identification, abundance and seasonal variation, Atmos. Environ., 27A, 1309-1330, 1993.

Saxena, P. and Hildemann, L. M.: Water-soluble organics in atmospheric particles: a critical review of the literature and application of thermodynamics to identify candidate compounds, J. Atmos. Chem., 24, 57-109, 1996.

Seinfeld, J. H. and Pandis, S. N.: Atmospheric Chemistry and Physics, John Wiley \& Sons, inc., 714-723, 1998.

Sempéré, R. and Kawamura, K.: Comparative distributions of dicarboxylic acids and related polar compounds in snow, rain and aerosols from urban atmosphere, Atmos. Environ., 28, 449-459, 1994.

Tao, Y. and McMurry, P. H.: Vapor pressures and surface free energies of C14-C18 monocarboxylic acids and C5 and C6 dicarboxylic acids, Environ. Sci. Technol., 23, 1519-1523, 1989.

Wexler, A. S. and Seinfeld, J. H.: The distribution of ammonium salts among a size and composition dispersed aerosol, Atmos. Environ., 24A, 1231-1246, 1990.

Wilhoit, R. C. and Zwolinski, B. J.: Handbook of Vapor Pressures and Heats of Vaporization of Hydrocarbons and related Compounds, Evans Press, Fort Worth, Texas, 1971.

Yaws, C. L.: Handbook of Vapor Pressure, Volumes 1, 2 and 3, Gulf Publishing Company, Houston, Texas, 1994.

Yu, J., Griffin, R. J., Cocker III, D. R., Flagan, R. C., Seinfeld, J. H., and Blanchard, P.: Observation of gaseous and particulate products of monoterpene oxidation in forest atmospheres, Geophys. Res. Lett., 26, 1145-1148, 1999.

Zappoli, S., Andracchio, A., Fuzzi, S., Facchini, M. C., Gelencsér, A., Kiss, G., Krivácsy, Z., Molnár, Á., Mészáros, E., Hansson, H.-C., Rosman, K., and Zebühr, Y.: Inorganic, organic and macromolecular components of fine aerosol in different areas of Europe in relation to their water solubility, Atmos. Environ., 33, 2733-2743, 1999. 